\title{
Oncogene DEK is highly expressed in lung cancerous tissues and positively regulates cell proliferation as well as invasion
}

\author{
QIAN-CHENG ZHOU ${ }^{1 *}$, XUE-FENG DENG ${ }^{2 *}$, JUAN YANG $^{1 *}$, HONG JIANG $^{1}$, MING-XU QIAO ${ }^{1}$, \\ HUAN-HUAN LIU ${ }^{1}$, ZHEN QIAN ${ }^{1}$, LING-LING HOU ${ }^{1}$ and HONG-GANG HU ${ }^{1}$ \\ ${ }^{1}$ College of Life Sciences and Bioengineering, School of Science, Beijing Jiaotong University, Beijing 100044; \\ ${ }^{2}$ Department of Cardio-Thoracic Surgery, Affiliated Hospital of Academy of \\ Military Medical Sciences, Beijing 100071, P.R. China
}

Received May 11, 2017; Accepted March 16, 2018

DOI: $10.3892 / 01.2018 .8436$

\begin{abstract}
DEK is a protein ubiquitously expressed in multicellular organisms as well as certain unicellular organisms. It is associated with the regulation of cell proliferation, differentiation, migration, apoptosis, senescence, self-renewal and DNA repairing. In tumor cells it is associated with the carcinogenesis process, however there have been few previous studies into the expression of DEK in lung cancer. In the present study the expression level of DEK mRNA and protein was detected in lung cancer tissues and non-cancerous counterparts by performing reverse transcription-quantitative polymerase chain reaction and immunohistochemical staining. It was revealed that the expression of DEK was increased in lung cancer tissues compared with normal tissue. Knock-down and over-expression of DEK in A549 cells were performed to determine the role of DEK in tumor formation. An MTT assay, colony formation assay and Matrigel invasion assay demonstrated that DEK positively regulated cell proliferation and invasion. These results suggest that DEK is highly expressed in lung cancer tissues and positively regulates cell proliferation and invasion.
\end{abstract}

\section{Introduction}

Lung cancer is the most prevalent type of cancer in the world. According to the World Health Organization (WHO), about 1.59 million cases of lung cancer-related deaths were recorded worldwide in 2012; and among those, 597 thousand cases took place in China. As a populated country with lots of risk factors such as smoking and air pollution, medical care departments in China is facing with a growing burden of cancer treatment.

Correspondence to: Dr Hong-Gang Hu, College of Life Sciences and Bioengineering, School of Science, Beijing Jiaotong University, 3 Shangyuancun, Haidian, Beijing 100044, P.R. China

E-mail: hghu@bjtu.edu.cn

*Contributed equally

Key words: DEK, lung cancer, carcinogenesis
Therefore, it is crucial to uncover the mechanism of lung cancer formation and thus develop new biomarkers for the detection and treatment of the disease. DEK is an ubiquitous protein in multicellular organisms as well as in some unicellular organisms (1). It was originally discovered as a fusion protein with CAN nucleoprotein in a subtype of acute myeloid leukemia in 1992 (2). Recent findings showed that DEK may act as an oncoprotein during tumor formation, because of its active role in regulating cell proliferation, differentiation, migration, apoptosis, senescence, self-renewal and DNA repairing (3). Meanwhile, it has been found that DEK is over-expressed in various malignant tumor cells, such as neuroendocrine prostate cancer cells, gastric adenocarcinoma cells, colorectal cancer cells, breast cancer cells, bladder cancer cells, human hepatocellular carcinoma cells and so on, while it remains in a low level or is even undetectable in quiescent and terminally differentiated cells (4-16). Over-expression of DEK boosts proliferation and transformation of epithelial cells, promotes tumor growth and metastasis of breast cancer cells, while it inhibits normal cell differentiation, suppresses p53 pathway-induced apoptosis and acts as a senescence inhibitor with E6 and E7 oncogene $(17,18)$. DEK depletion, on the other hand, may trigger cell apoptosis or senescence (19-23), and also sensitize cells to chemotherapy or genotoxic agents (9,23-26). These facts demonstrate the potential applications of DEK as a tumor diagnostic biomarker and also as a therapeutic target.

This study focused on the poorly understood function of DEK in lung cancer cells, and discovered the clinical pathological significance of DEK in lung cancer detection and treatment.

\section{Materials and methods}

Clinical samples and ethics statement. In this study, 81 specimens of surgically resected lung tumors as well as corresponding adjacent precancerous tissue (with $30 \mathrm{~cm}$ distance from the tumor's edge) and/or normal tissues (with $50 \mathrm{~cm}$ distance from the tumor's edge) were collected at the Fourth Military Medical University Affiliated Tangdu Hospital and the General Hospital of People's Liberation Army from December 2010 to November 2014 after receiving the patients' informed consent and the approval of hospital authorities. None of the patients received radiotherapy or chemotherapy 
prior to the pulmonary surgery. After surgical removal, all of the samples were immediately snap-frozen in liquid nitrogen and stored at $-80^{\circ} \mathrm{C}$ for RNA (29 cases) and protein analyses. All cancerous tissues were primary tumors according to the International Union against Cancer guidelines. The Beijing Jiaotong University Institutional Review Board approved the present study.

Cell cultures, siRNAs and plasmids. A549 cell line was obtained from American Type Culture Collection (Manassas, VA, USA). Cells were cultured in Dulbecco's Modified Eagle Medium (DMEM; Invitrogen; Thermo Fisher Scientific, Inc., Waltham, MA, USA) with $10 \%$ fetal bovine serum (FBS) and were passaged every 3 days using $0.25 \%$ trypsin (Merck KGaA, Darmstadt, Germany). The siRNA targeting DEK CDS region was synthesized by Invitrogen, and it was transfected into A549 cells using Lipofectamine 3000 (Invitrogen; Thermo Fisher Scientific, Inc.) according to the manufacturer's protocol. Sequences of the siRNAs are listed (Table I). The pcDNA3.1-hDEK plasmid was constructed using the pcDNA3.1 (-) plasmid and the DEK CDS sequence with a 6xCAT Histidine Tag at its N-terminal. A corresponding negative control plasmid was constructed with an EGFP CDS sequence replacing the His-DEK, and it acted as a positive control for the transfection.

RNA extraction and reverse transcription-PCR. Total RNA was extracted from the lung tumor and matched non-tumorous tissues using Trizol reagent (Invitrogen; Thermo Fisher Scientific, Inc.). A total of $1.5 \mu \mathrm{g} \mathrm{mRNA}$ aliquot from each sample were reverse transcribed to double-stranded cDNAs using Go Script ${ }^{\mathrm{TM}}$ Reverse Transcription System (Promega Corporation, Madison, WI, USA) with the final volume of $20 \mu \mathrm{l}$. Quantitative reverse transcription-PCR (qRT-PCR) was performed using Super Real PreMix Plus (SYBR Green; Tiangen Biotech Co., Ltd., Beijing, China) and Light Cycler 480 (Roche Diagnostics, Indianapolis, IN, USA) according to the manufacturer's protocol. cDNAs were diluted into quarters and $1 \mu \mathrm{l}$ of diluted cDNAs were added into the reaction mix with the final volume of $20 \mu \mathrm{l}$. Reaction conditions were as followed: $95^{\circ} \mathrm{C} 15 \mathrm{~min}$; followed by 40 cycles of $95^{\circ} \mathrm{C} 10 \mathrm{sec}$, $60^{\circ} \mathrm{C} 20 \mathrm{sec}$ (signal acquisition). Experiment was performed in triplicates and the fold change of each gene was calculated using the $2^{-\Delta \Delta \mathrm{Ct}}$ method. Primers used in this experiment are listed (Table II).

Immunohistochemistry. Immunohistochemistry (IHC) was performed on formalin-fixed paraffin-embedded tumor tissues, which were sectioned (4 $\mathrm{mm}$ ) and mounted on polylysine-coated slides. The sections were deparaffinized in xylene and then rehydrated in decreasing concentrations of ethanol (100, 95, 80 and 70\%, respectively). Antigen was retrieved by incubating sections with sodium citrate buffer $(\mathrm{pH}$ 6.0) for $10 \mathrm{~min}$ in the microwave. Slides were incubated with $3 \%(\mathrm{v} / \mathrm{v})$ $\mathrm{H}_{2} \mathrm{O}_{2}$ for 15 min to inhibit endogenous peroxidase activity. To further reduce non-specific background staining, sections were incubated in $20 \%$ (v/v) normal goat serum for $20 \mathrm{~min}$ and were then incubated with the DEK-specific primary rabbit antibody (dilution 1:300; ProteinTech Group, Inc., Chicago, IL, USA) at $37^{\circ} \mathrm{C}$ for $2 \mathrm{~h}$. The Goat anti Rabbit IgG/HRP polymer conjugate (OriGene Technologies, Inc., Rockville, MD, USA) were added to the sections and incubated at $37^{\circ} \mathrm{C}$ for 15 min according to the manufacturer's protocol. Between each aforementioned steps, the sections were washed with phosphate-buffered saline (PBS) for 6 min. Immunostaining was visualized by developing the slides in diaminobenzidin (DAB). The sections were counterstained with hematoxylin for $4 \mathrm{sec}$, dehydrated and mounted. Each slide was observed under the microscope at magnification, $x 400$. Semi-quantitative percentage score was given according to the nuclear staining of cells from five views. Percentage scores were assigned as follows: 0-5\%: negative (-), 6-25\%: weak positive $(+), 26-50 \%$ : positive $(++)$, 51-100\%: strong positive (+++).

Western blotting analysis. Cells were trypsinized after transfection for $48 \mathrm{~h}$ using $0.25 \%$ trypsin (Merck KGaA), then lysed using 1X SDS-PAGE loading buffer [0.045 mol/1 Tris-HCl (pH 6.8); $10 \%$ glycerin, $1 \%$ SDS; $0.004 \%$ bromophenol blue; $0.5 \mathrm{~mol} / 1 \mathrm{DTT}$; with a final concentration of $200 \mu \mathrm{l}$ loading buffer every $1 \times 10^{6}$ cells]. $30 \mu \mathrm{l}$ of each sample was loaded and separated in a $12 \%$ SDS-polyacrylamide gel by electrophoresis. Proteins were transferred onto nitrocellulose filter membrane (NC membrane; Pall Life Sciences, Port Washington, NY, USA) and incubated in the following reagents: $5 \%$ non-fat milk ( $4^{\circ} \mathrm{C}$, over-night); primary antibodies (DEK rabbit polyclonal antibody: 1:1,000, ProteinTech Group, Inc.; $\beta$-actin mouse monoclonal antibody: 1:1,000, OriGene Technologies, Inc.; His mouse monoclonal antibody: 1:500, OriGene Technologies, Inc.); secondary antibodies (Peroxidase-Conjugated AffiniPure Goat anti-mouse IgG: 1:2,000, OriGene Technologies, Inc.; or Peroxidase-Conjugated AffiniPure Goat anti-rabbit IgG: 1:2,000, OriGene Technologies, Inc.; $\left.37^{\circ} \mathrm{C}, 1 \mathrm{~h}\right)$. After each aforementioned incubation step, the membrane was washed in TBST buffer for 3 times, 5 min each time. So were the reagent and antibodies diluted in TBST buffer. After the final washing step, bound proteins were visualized using ECL (Thermo Fisher Scientific, Inc.) and X-ray film (Fujifilm, Shanghai, China). The relative expression level of each gene was analyzed based on $\beta$-actin as the loading control.

MTT assay. A549 cells were planted on 96-well plate before transfection, with $100 \mu \mathrm{l}$ of medium, 1,000 cells per well. $10 \mu \mathrm{l}$ MTT reagent was added to wells 24, 48, 72 and $96 \mathrm{~h}$ after transfection, and the plate was incubated in $37^{\circ} \mathrm{C}$ for $4 \mathrm{~h}$. After discarding the media, $100 \mu \mathrm{l}$ of DMSO was added to dissolve the MTT formazan in each well. The plate was incubated in $37^{\circ} \mathrm{C}$ for another $4 \mathrm{~h}$ and the optical density was read using a wavelength of $570 \mathrm{~nm}$. Each test was performed in triplicates.

Colony formation assay. Cells were replanted in 6-well cell culture dishes $48 \mathrm{~h}$ after transfection with 1,000 cells per well. Medium was renewed every two days. 7 days after transfection, colonies were stained by $0.1 \%$ crystal violet (Beyotime Institute of Biotechnology, Haimen, China), and visible colonies were counted. Each test was performed in triplicates.

Matrigel cell invasion assay. $48 \mathrm{~h}$ after transfection, 10,000 cells were replanted onto the upper membrane of transwell chamber (EMD Millipore, Billerica, MA, USA) covered with Matrigel (BD Biosciences, Franklin Lakes, NJ, USA) according to the manufacturer's protocol. The upper chamber 
Table I. List of siRNA sequences.

\begin{tabular}{lll}
\hline Name & \multicolumn{1}{c}{ Sense-strand sequence (5' to 3') } & Antisense-stand sequence (5' to 3') \\
\hline $\begin{array}{l}\text { siRNA-DEK } \\
\text { siRNA-NC }\end{array}$ & GGAUAGUUCAGAUGAUGAACCdTdT & GGUUCAUCAUCUGAACUAUCC dTdT \\
\hline
\end{tabular}

siRNA, short interfering RNA.

Table II. Primers used in the experiment.

\begin{tabular}{llc}
\hline Name of primer & \multicolumn{1}{c}{ Sequence (5' to 3') } & Product size (bp) \\
\hline DEK-Fw & TGTTAAGAAAGCAGATAGCAGCACC & 96 \\
DEK-Rv & ATTAAAGGTTCATCATCTGAACTATCCTC & \\
B2M-Fw & GGCTATCCAGCGTACTCC & 247 \\
B2M-Rv & ACGGCAGGCATACTCATC & 123 \\
GAPDH-Fw & TGACATCAAGAAGGTGGTGAAGCAGG & \\
GAPDH-Rv & GCGTCAAAGGTGGAGGAGTGGGT \\
p53-Fw & GCGAGCACTGCCCAACAACA & 83 \\
p53-Rv & GGATCTGAAGGGTGAAATATTCT & 152 \\
p65-Fw & ATGTGGAGATCATTGAGCAGC & 142 \\
p65-Rv & CCTGGTCCTGTGTAGCCATT & 388 \\
ATM-Fw & TTGATCTTGTGCCTTGGCTAC & 38 ATM-Rv \\
DEK-BSP-Fw & TATGGTGTACGTTCCCCATGT & \\
DEK-BSP-Rv & GGGATTGTTTATTATTTTTTTAGGAAG & \\
\hline
\end{tabular}

contained $200 \mu \mathrm{l}$ of DMEM, and the lower chamber contained $600 \mu \mathrm{l}$ of DMEM with $10 \%$ FBS as chemoattractant. $24 \mathrm{~h}$ after incubation, the chamber was washed with PBS and cells on the upper membrane were gently removed. Then the membrane was stained with crystal violet (Beyotime Institute of Biotechnology, Haimen, China). Number of migrated cells were counted under the microscope with magnification, $\mathrm{x} 100$, 5 randomly selected areas on each membrane were counted.

Statistical analysis. All data were analyzed using SPSS version 20. Immunohistochemistry results were analyzed using the chi-squared tests, and all other results were analyzed using the unpaired, two-tailed Student's t-tests. All statistical data were presented as means \pm standard deviation. A test with a $\mathrm{P}<0.05$ was considered to indicate a statistically significant difference.

\section{Results}

Over-expression of DEK $m R N A$ detected in lung cancerous tissues. Real-time quantitative RT-PCR (qRT-PCR) was performed in 29 cases of lung cancerous tissues paired with non-cancerous counterparts. DEK-over expression means that in tumor samples the DEK is more expressed than in the adjacent normal tissue samples. As shown in Table III, DEK mRNA was over-expressed in 15 out of $29(51.7 \%)$ cases of lung cancerous tissues paired with normal tissues. Among those, 14 cases (48.3\%) showed over two-fold up-regulation of DEK mRNA level, 9 cases $(31.0 \%)$ showed over five-fold up-regulation of DEK mRNA level. In adenocarcinoma tissues, 7 out of 8 cases $(87.5 \%)$ showed over-expression of DEK mRNA, which was significantly higher than those of other histopathological types. However, no correlation between the over-expression of DEK mRNA and patient's age, gender, pleural invasion status as well as TMN stage was found (Table IV).

Over-expression of DEK protein detected in lung cancerous tissues. The expression level of DEK protein in lung cancerous tissues and non-cancerous counterparts were detected by IHC (Fig. 1). Among 81 cases of lung cancerous tissues, 66 cases $(81.5 \%)$ showed positive staining of DEK protein, while 32 cases $(39.5 \%)$ showed strong positive staining of DEK protein, which was significantly higher than those in normal tissues (Table V). However, there was no significant correlation between strong positive staining of DEK protein and clinicopathological characteristics of patients (Table VI).

DEK depletion and over-expression in A549 lung cancer cells. To further investigate the function of DEK in lung cancer cells, siRNA as well as plasmid encoding His-tagged DEK CDS were employed respectively to down-regulate and up-regulate the expression level of DEK in A549 lung cancer cell line. The expression level of DEK mRNA and protein were analyzed by qRT-PCR and Western Blotting (WB). Results showed the expression level of DEK mRNA and 
Table III. Association between DEK mRNA expression and tissue position.

\begin{tabular}{lccc}
\hline Groups compared & Cases & DEK over-expressed (\%) & DEK not over-expressed (\%) \\
\hline Cancerous/normal tissue & 29 & $15(51.7)$ & $14(48.3)$ \\
Cancerous/precancerous tissue & 30 & $11(36.7)$ & $19(63.3)$ \\
Precancerous/normal tissue & 24 & $10(41.7)$ & $14(58.3)$ \\
\hline
\end{tabular}

Table IV. Association between DEK mRNA expression and clinicopathological characteristics.

\begin{tabular}{|c|c|c|c|c|c|}
\hline Clinicopathological characteristic & Cases & DEK over-expressed (\%) & DEK not over-expressed (\%) & $\chi^{2}$ & P-value \\
\hline Total & 29 & $15(51.7)$ & $14(48.3)$ & & \\
\hline Age & & & & 0.181 & 0.671 \\
\hline$\leq 60$ & 12 & $7(58.3)$ & $5(41.7)$ & & \\
\hline$>60$ & 14 & $7(50.0)$ & $7(50.0)$ & & \\
\hline Unknown & 3 & $1(33.3)$ & $2(66.7)$ & & \\
\hline Gender & & & & 0.379 & 0.678 \\
\hline Male & 19 & $11(57.9)$ & $8(42.1)$ & & \\
\hline Female & 7 & $3(42.9)$ & $4(57.1)$ & & \\
\hline Unknown & 3 & $1(33.3)$ & $2(66.7)$ & & \\
\hline Pleural invasion & & & & 0.422 & 0.516 \\
\hline Positive & 10 & $6(60.0)$ & $4(40.0)$ & & \\
\hline Negative & 17 & $8(47.1)$ & $9(52.9)$ & & \\
\hline Unknown & 2 & $1(50.0)$ & $1(50.0)$ & & \\
\hline Histopathological type & & & & 8.471 & 0.132 \\
\hline NSCLC & 22 & $12(54.5)$ & $10(45.5)$ & 0.049 & $>0.999$ \\
\hline Adenocarcinoma & 8 & $7(87.5)$ & $1(12.5)$ & 4.698 & $0.043^{\mathrm{a}}$ \\
\hline Squamous carcinoma & 9 & $3(33.3)$ & $6(66.7)$ & & \\
\hline Adenosquamous carcinoma & 2 & $1(50.0)$ & $1(50.0)$ & & \\
\hline Sarcomatoid carcinoma & 2 & $0(0.0)$ & $2(100.0)$ & & \\
\hline Large cell carcinoma & 1 & $1(100.0)$ & $0(0.0)$ & & \\
\hline Small cell carcinoma & 5 & $3(60.0)$ & $2(40.0)$ & & \\
\hline Unknown & 2 & $0(0.0)$ & $2(100.0)$ & & \\
\hline TMN & & & & 2.912 & 0.573 \\
\hline Benign tumor & 1 & $0(0.0)$ & $1(100.0)$ & & \\
\hline I & 10 & $6(60.0)$ & $4(40.0)$ & & \\
\hline II & 7 & $4(57.1)$ & $3(42.9)$ & & \\
\hline III & 10 & $4(40.0)$ & $6(60.0)$ & & \\
\hline IV & 1 & $1(100.0)$ & $0(0.0)$ & & \\
\hline \multicolumn{6}{|l|}{ Differentiation } \\
\hline Well to moderately-well & 4 & $4(100.0)$ & $0(0.0)$ & & \\
\hline Moderate to poor & 3 & $3(100.0)$ & $0(0.0)$ & & \\
\hline Unknown & 1 & $0(0.0)$ & $1(100.0)$ & & \\
\hline
\end{tabular}

${ }^{\mathrm{a}} \mathrm{P}<0.05$ vs. non-adenocarcinoma samples. NSCLC, non-small cell lung cancer; TNM, tumor, node, metastasis.

protein were down-regulated by siRNA transfection; while the transfection of plasmid encoding His-tagged DEK caused DEK over-expression in A549 cells (Fig. 2).

DEK positively regulates proliferation in A549 cells. To detect whether DEK could regulate cell proliferation in lung cancer cell lines, MTT assay was performed in DEK depleted and over-expressed A549 cells. Results showed that cell proliferation was significantly restricted after day 4 in DEK depleted cells, while being significantly promoted after day 3 and day 4 in DEK over-expressed cells (Fig. 3A and B). A supplementary experiment of colony formation assay was performed and the 
Table V. Association between DEK protein expression and tissue position according to immunohistochemistry results.

\begin{tabular}{lccccccc}
\hline Sample & Cases & - & + & ++ & +++ & Positive rate $(\%)$ & Strong positive rate $(\%)$ \\
\hline C & 81 & 15 & 34 & 21 & 11 & 81.5 & $39.5^{\mathrm{a}}$ \\
$\mathrm{P}$ & 81 & 13 & 45 & 21 & 2 & 84.0 & 28.4 \\
$\mathrm{~N}$ & 73 & 23 & 35 & 13 & 2 & 68.5 & 20.5
\end{tabular}

${ }^{\mathrm{a}} \mathrm{P}<0.05$ vs. normal tissues samples.,$- 0-5 \% ;+, 6-25 \% ;++, 26-50 \% ;+++, 51-100 \%$. C, Cancerous tissue sample; $\mathrm{P}$, adjacent precancerous tissue sample; $\mathrm{N}$, normal tissue sample.

Table VI. Association between DEK protein expression and clinicopathological characteristics.

\begin{tabular}{|c|c|c|c|c|c|}
\hline $\begin{array}{l}\text { Clinicopathological } \\
\text { characteristic }\end{array}$ & Cases & $\begin{array}{l}\text { Strong positive } \\
\text { staining of } \\
\text { DEK in } \\
\text { cancerous tissues, } \\
+++ \text { or }++(\%)\end{array}$ & $\begin{array}{l}\text { Weak or negative } \\
\text { staining of } \\
\text { DEK in } \\
\text { cancerous tissues, } \\
+ \text { or }-(\%)\end{array}$ & $\chi^{2}$ & P-value \\
\hline Total & 81 & $32(39.5)$ & $49(60.5)$ & & \\
\hline Age & & & & 2.339 & 0.126 \\
\hline$\leq 60$ & 40 & $14(35.0)$ & $26(65.0)$ & & \\
\hline$>60$ & 30 & $16(53.3)$ & $14(46.7)$ & & \\
\hline Unknown & 11 & $2(18.2)$ & $9(81.8)$ & & \\
\hline Gender & & & & 2.500 & 0.114 \\
\hline Male & 49 & $24(49.0)$ & $25(51.0)$ & & \\
\hline Female & 21 & $6(28.6)$ & $15(71.4)$ & & \\
\hline Unknown & 11 & $2(18.2)$ & $9(81.8)$ & & \\
\hline Pleural invasion & & & & 0.002 & 0.968 \\
\hline Positive & 16 & $10(62.5)$ & $6(37.5)$ & & \\
\hline Negative & 19 & $12(63.2)$ & $7(36.8)$ & & \\
\hline Unknown & 46 & $10(21.7)$ & $36(78.3)$ & & \\
\hline Histopathological type & & & & 5.344 & 0.375 \\
\hline NSCLC & 61 & $25(41.0)$ & $36(59.0)$ & 0.039 & $>0.999$ \\
\hline Adenocarcinoma & 24 & 7 (29.2) & $17(70.8)$ & & \\
\hline Squamous carcinoma & 24 & $11(45.8)$ & $13(54.2)$ & & \\
\hline Adenosquamous carcinoma & 4 & $2(50.0)$ & $2(50.0)$ & & \\
\hline Sarcomatoid carcinoma & 5 & $4(80.0)$ & $1(20.0)$ & & \\
\hline Large cell carcinoma & 4 & $1(25.0)$ & $3(75.0)$ & & \\
\hline Small cell carcinoma & 9 & $4(44.4)$ & $5(55.6)$ & & \\
\hline Unknown & 11 & $3(27.3)$ & $8(72.7)$ & & \\
\hline $\mathrm{TMN}$ & & & & 2.167 & 0.705 \\
\hline Benign tumor & 1 & $1(100.0)$ & $0(0.0)$ & & \\
\hline I & 19 & $8(42.1)$ & $11(57.9)$ & & \\
\hline II & 12 & $6(50.0)$ & $6(50.0)$ & & \\
\hline III & 25 & $14(56.0)$ & $11(44.0)$ & & \\
\hline IV & 3 & $1(33.3)$ & $2(66.7)$ & & \\
\hline Unknown & 21 & $2(9.5)$ & $19(90.5)$ & & \\
\hline Differentiation & & & & 0.198 & 0.673 \\
\hline Well to moderately-well & 9 & $3(33.3)$ & $6(66.7)$ & & \\
\hline Moderate to poor & 16 & $4(25.0)$ & $12(75.0)$ & & \\
\hline Unknown & 56 & $25(44.6)$ & $31(55.4)$ & & \\
\hline
\end{tabular}

,$- 0-5 \% ;+, 6-25 \% ;++, 26-50 \% ;+++, 51-100 \%$. NSCLC, non-small cell lung cancer; TNM, tumor, node, metastasis. 

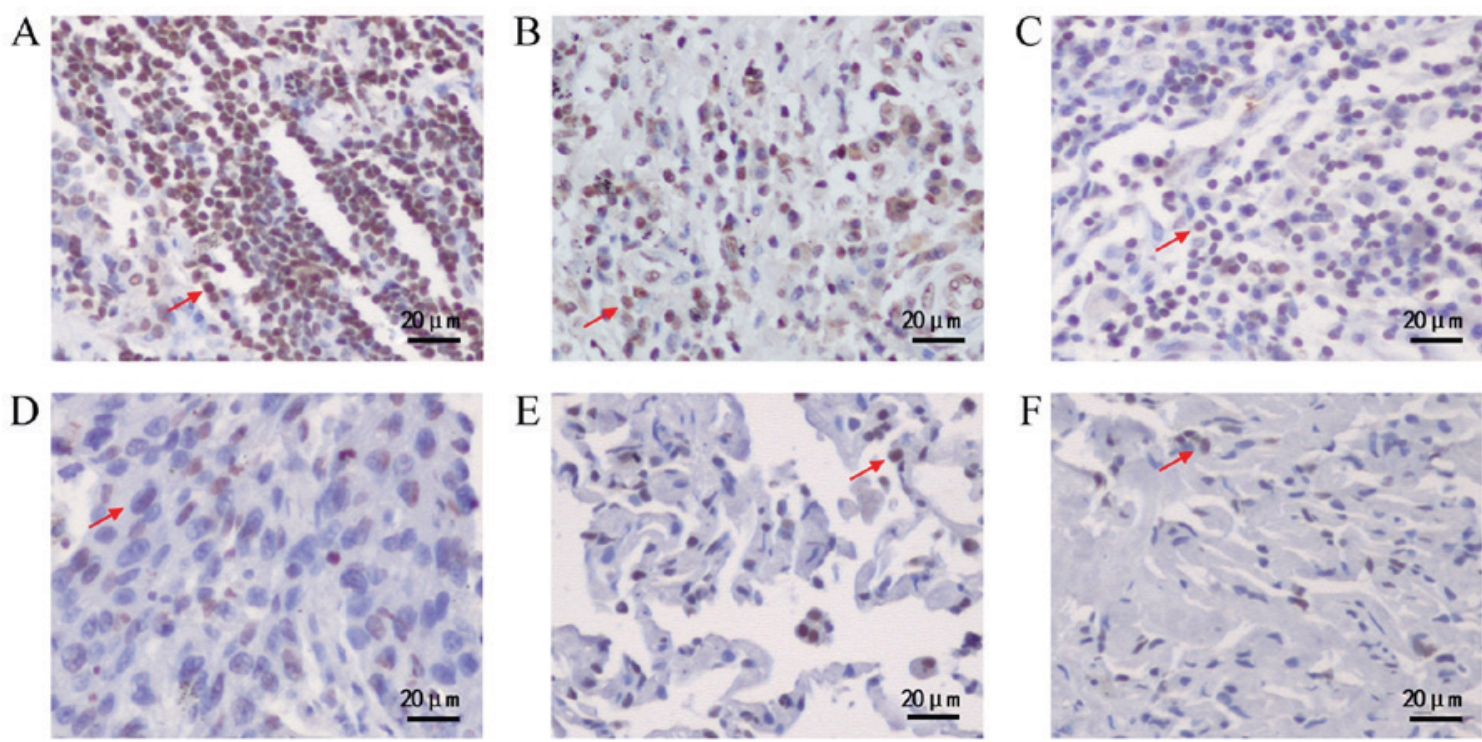

Figure 1. Detection of DEK protein in lung cancerous tissues. (A) Strong positive staining (+++) of DEK protein in lung cancerous tissues. (B) Positive staining (++), (C) weak positive staining (+) and (D) negative staining (-) of DEK protein in lung cancerous tissues. (E) Precancerous and (F) normal tissues corresponding to the cancerous tissue in part A. Each showing negative staining of the DEK protein. Each slide was observed under the microscope at magnification, x400. Semi-quantitative percentage score was given according to the nuclear staining of cells from five views. Arrows in the pictures indicate a positive stain. Scale bars, $20 \mu \mathrm{m}$.

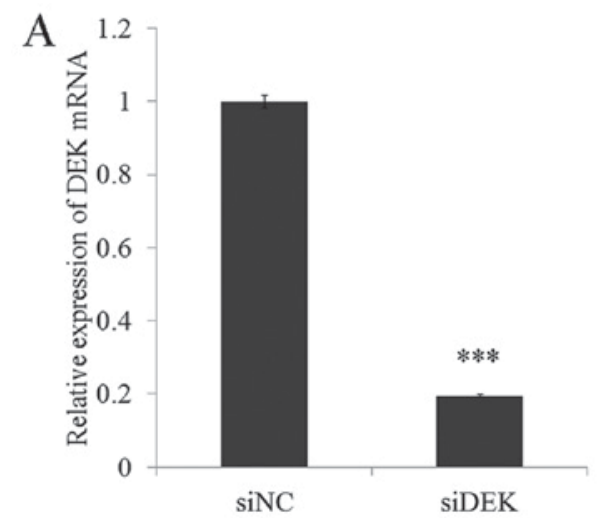

B

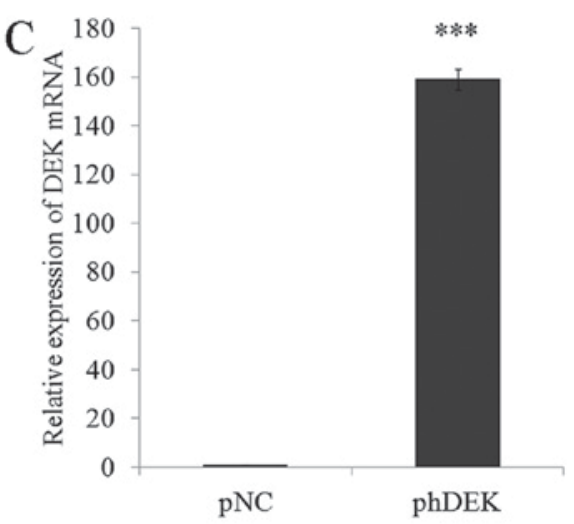

DEK

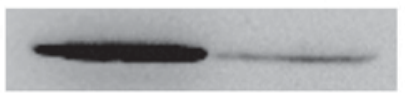

$\beta$-actin

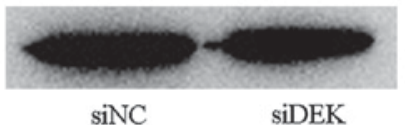

$\mathrm{D}$

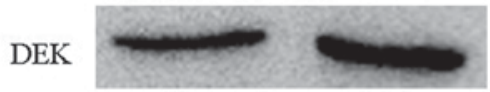

His

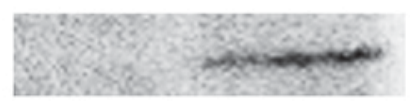

$\beta$-actin

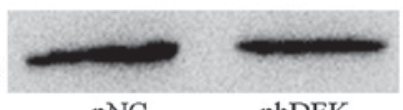

phDEK

Figure 2. Depletion and over-expression of DEK in A549 cells. The expressional level of DEK mRNA and protein was analyzed $48 \mathrm{~h}$ post transfection. A549 cells transfected with DEK-targeting siRNA showed significant decrease in DEK (A) mRNA and (B) protein expressional level compared with the control group. A549 cells transfected with DEK over-expressing plasmid showed a significant increase in DEK (C) mRNA and (D) protein expressional level compared with the control group. Anti-His tag antibodies were used to verify whether the over-expressing DEK was the product of the plasmid transfected. ${ }^{* * *} \mathrm{P}<0.001$ vs. the control.

results were in accordance with the former one. A significant decrease of colony numbers in DEK depleted cells and a significant increase of colony numbers in DEK over-expressed cells were detected (Fig. 3C-F). Both experiments manifested 

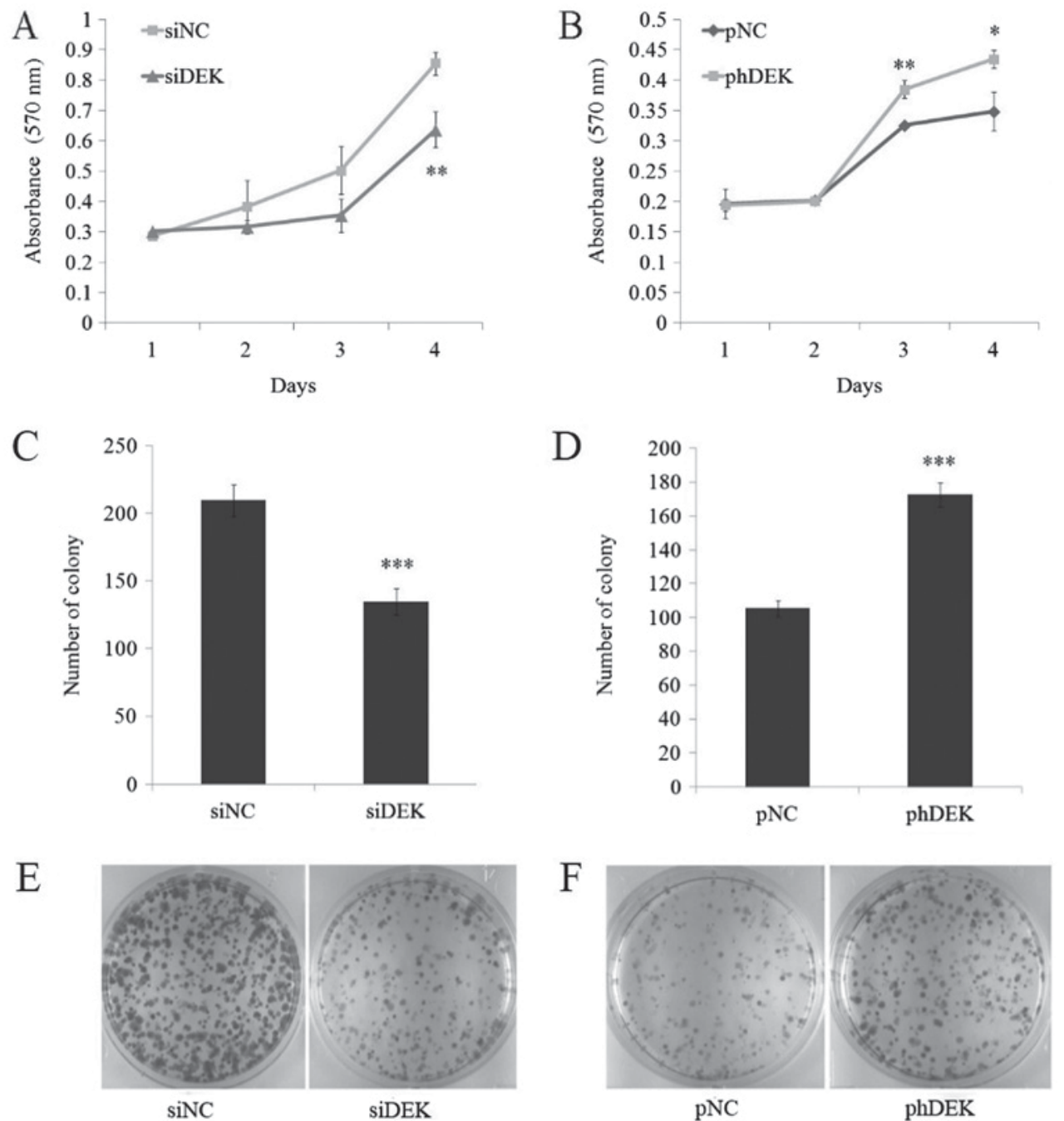

Figure 3. DEK positively regulates A549 cell proliferation. An MTT assay revealed (A) a reduction of $570 \mathrm{~nm}$ absorbance in DEK depleted cells after day 4 (B) and an increased absorbance in DEK over-expressed cells after day 3 and day 4 . The colony formation assay revealed that (C) fewer colonies were formed after DEK was depleted (D) while more colonies were formed after the over-expression of DEK. Both assays were performed in triplicate. The colonies were stained by crystal violet in the (E) siDEK and (F) pDEK groups of treated cells. ${ }^{*} \mathrm{P}<0.05,{ }^{* *} \mathrm{P}<0.01$ and ${ }^{* * * *} \mathrm{P}<0.001$ vs. the control. si, short interfering; $\mathrm{p}$, plasmid.
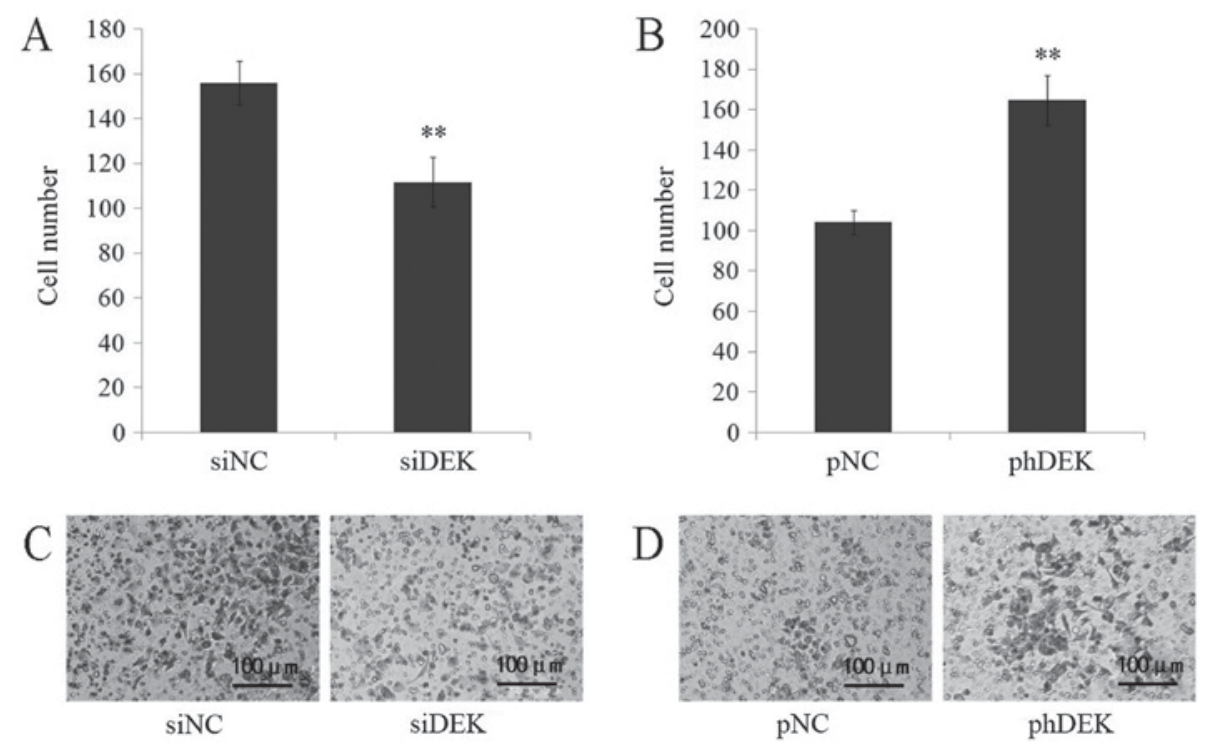

Figure 4. DEK positively regulates the invasion of A549 lung cancer cell. Cell invasion was (A) significantly inhibited in DEK-depleted A549 cells, while (B) significantly promoted in DEK over-expressed cells. The assay was performed in triplicates. Cells migrated to the lower surface of the chamber were stained by crystal violet in the (C) siDEK and (D) pDEK groups of treated cells. Scale bars, $100 \mu \mathrm{m}$. ${ }^{* *} \mathrm{P}<0.01 \mathrm{vs}$. the control. si, short interfering; $p$, plasmid. 
the positive correlation between DEK expressional level and cell proliferation, showing DEK may act as a pro-proliferation factor in A549 cells. As a chromatin associated architectural protein, DEK may play an important role in change of chromatin structure and thereby the expression of genes related to cell proliferation.

DEK positively regulates invasion of A549 cells. Matrigel invasion assay was performed to detect alterations DEK made to cell invasion. Decrease of invaded cell numbers was shown in DEK depleted A549 cells, while DEK over-expressed cells resulted in an increase of invaded cell numbers (Fig. 4). According to the results, the invasion of A549 cells was positively correlated with DEK expression.

\section{Discussion}

DEK is over-expressed in various type of malignant carcinomas, such as acute myeloid leukemia, retinoblastoma, brain malignant glioma, hepatocellular carcinoma, breast cancer, uterine cervical cancer, bladder cancer, colon cancer, colorectal cancer, gastric adenocarcinoma, oral squamous cell carcinoma, neuroendocrine prostate cancer $(5-8,10-17,27)$. It was first discovered that DEK was over-expressed in high-grade neuroendocrine carcinoma of the lung by Shibata et al (9), yet it was only limited on the type of neuroendocrine carcinoma. Here we examined the expression level of DEK in various subtypes of lung cancer, and discovered that DEK mRNA is over-expressed in $51.7 \%$ of lung cancerous tissues. Especially, in adenocarcinoma tissues of the lung, DEK showed a significantly high over-expression rate of $87.5 \%$. The IHC experiment showed similar results, $39.5 \%$ of lung cancerous tissues showed strong positive expression of DEK protein, while the number was only $20.5 \%$ in normal tissues. These findings gave valuable hints to the biomarker development of DEK, showing that DEK might have the potential to be applied as a diagnostic biomarker for lung cancers, especially for adenocarcinoma of the lung. However, neither of these studies demonstrated the relationship between DEK expression and patient's age, gender, or TMN stage, differentiation status of the carcinoma.

We have analyzed the expression of DEK in mRNA and protein level in lung cancer samples, not only the NSCLC samples reported in the study by Liu et al (28), which explored the role of DEK expression for the prognostic evaluation of non-small cell lung carcinoma (NSCLC). Besides, based on the previous findings, the downstream effects of aberrant DEK expressional level were analyzed using the A549 lung cancer cell line. Through silence and overexpression of DEK in A549 cells, we found that DEK could influence the proliferation and invasion of A549 tumor cells. In our study, it was discovered that the over-expression of DEK promotes cell proliferation and invasion, which was in accordance with former studies in other types of cancers $(3,8,17,19)$. The findings support the carcinogenic role of DEK in lung cancer formation, and it could be the reason for the aberrant expressional level of DEK in lung cancerous tissues we detected earlier. On the other hand, depletion of DEK in A549 cells gave us the exact opposite story. Our study showed that DEK depletion could repress proliferation and invasion of lung tumor cells. Therefore, DEK could act as a target for lung tumor therapy applied in clinical studies. In our study, the depletion of the gene expression was accomplished by siRNA transfection, which made the therapy easier to be applied clinically.

To sum up, the present study discovered that DEK was over-expressed in lung cancerous tissues. The aberrant expression of DEK may promote cell survival and tumorigenesis. The more detailed discussion of DEK's mechanism in lung cancer formation should be done in the future studies, and clinical studies using larger groups of samples should be performed to discover the further application value of DEK as a novel biomarker.

\section{Acknowledgements}

Not applicable.

\section{Funding}

This study has been funded by the National Natural Science Foundation of China (grant no. 81201762).

\section{Availability of data and material}

The datasets used and/or analyzed during the current study are available from the corresponding author on reasonable request.

\section{Author's contributions}

QCZ, JY, MXQ, HHL and ZQ performed the experiments and analyzed the data. XFD contributed to the collection of human lung tissue samples and RNA extraction. LLH, HJ and HGH conceived and designed the study. QCZ and JY drafting the manuscript, which was critically revised by LLH and HGH.

\section{Ethics approval and consent to participate}

The present study was approved by the Beijing Jiaotong University Institutional Review Board. Written informed consent was obtained from all patients prior to their inclusion.

\section{Consent for publication}

Informed consent was obtained from all patients' for the publication of their data.

\section{Competing interests}

The authors declare that they have no competing interests.

\section{References}

1. Waldmann T, Scholten I, Kappes F, Hu HG and Knippers R: The DEK protein-an abundant and ubiquitous constituent of mammalian chromatin. Gene 343: 1-9, 2004.

2. von Lindern M, Breems D, van Baal S, Adriaansen $H$ and Grosveld G: Characterization of the translocation breakpoint sequences of two DEK-CAN fusion genes present in $\mathrm{t}(6 ; 9)$ acute myeloid leukemia and a SET-CAN fusion gene found in a case of acute undifferentiated leukemia. Genes Chromosomes Cancer 5: 227-234, 1992. 
3. Privette Vinnedge LM, Kappes F, Nassar N and Wells SI Stacking the DEK: From chromatin topology to cancer stem cells. Cell Cycle 12: 51-66, 2013.

4. Grottke C, Mantwill K, Dietel M, Schadendorf D and Lage H: Identification of differentially expressed genes in human melanoma cells with acquired resistance to various antineoplastic drugs. Int J Cancer 88: 535-546, 2000.

5. Wang X, Huang SH, Yu LQ, Liu J, Diao Y and Sun CF: Relationship between DEK oncogene expression and oral squamous cell carcinoma. Shanghai Kou Qiang Yi Xue 23: 75-79, 2014 (In Chinese)

6. Piao J, Shang Y, Liu S, Piao Y, Cui X, Li Y and Lin Z: High expression of DEK predicts poor prognosis of gastric adenocarcinoma. Diagn Pathol 9: 67, 2014.

7. Lin L, Piao J, Gao W, Piao Y, Jin G, Ma Y, Li J and Lin Z: DEK over expression as an independent biomarker for poor prognosis in colorectal cancer. BMC Cancer 13: 366, 2013.

8. Privette Vinnedge LM, McClaine R, Wagh PK, Wikenheiser-Brokamp KA, Waltz SE and Wells SI: The human DEK oncogene stimulates $\beta$-catenin signaling, invasion and mammosphere formation in breast cancer. Oncogene 30: 2741-2752, 2011

9. Shibata T, Kokubu A, Miyamoto M, Hosoda F, Gotoh M, Tsuta K, Asamura H, Matsuno Y, Kondo T, Imoto I, et al: DEK oncoprotein regulates transcriptional modifiers and sustains tumor initiation activity in high-grade neuroendocrine carcinoma of the lung. Oncogene 29: 4671-4681, 2010.

10. Wu Q, Li Z, Lin H, Han L, Liu S and Lin Z: DEK overexpression in uterine cervical cancers. Pathol Int 58: 378-382, 2008.

11. Orlic M, Spencer CE, Wang L and Gallie BL: Expression analysis of $6 \mathrm{p} 22$ genomic gain in retinoblastoma. Genes Chromosomes Cancer 45: 72-82, 2006.

12. Carro MS, Spiga FM, Quarto M, Di Ninni V, Volorio S, Alcalay M and Müller H: DEK Expression is controlled by E2F and deregulated in diverse tumor types. Cell Cycle 5: 1202-1207, 2006.

13. Sanchez-Carbayo M, Socci ND, Lozano JJ, Li W, Charytonowicz E, Belbin TJ, Prystowsky MB, Ortiz AR, Childs G and Cordon-Cardo C: Gene discovery in bladder cancer progression using cDNA microarrays. Am J Pathol 163: 505-516, 2003.

14. Larramendy ML, Niini T, Elonen E, Nagy B, Ollila J, Vihinen M and Knuutila S: Overexpression of translocation-associated fusion genes of FGFRI, MYC, NPMI, and DEK, but absence of the translocations in acute myeloid leukemia. A microarray analysis. Haematologica 87: 569-577, 2002.

15. Kroes RA, Jastrow A, McLone MG, Yamamoto H, Colley P, Kersey DS, Yong VW, Mkrdichian E, Cerullo L, Leestma J and Moskal JR: The identification of novel therapeutic targets for the treatment of malignant brain tumors. Cancer Lett 156: 191-198, 2000

16. Kondoh N, Wakatsuki T, Ryo A, Hada A, Aihara T, Horiuchi S, Goseki N, Matsubara O, Takenaka K, Shichita M, et al: Identification and characterization of genes associated with human hepatocellular carcinogenesis. Cancer Res 59: 4990-4996, 1999.

17. Wise-Draper TM, Mintz-Cole RA, Morris TA, Simpson DS, Wikenheiser-Brokamp KA, Currier MA, Cripe TP, Grosveld GC and Wells SI: Overexpression of the cellular DEK protein promotes epithelial transformation in vitro and in vivo. Cancer Res 69: 1792-1799, 2009.
18. Wise-Draper TM, Allen HV, Thobe MN, Jones EE, Habash KB, Münger K and Wells SI: The human DEK proto-oncogene is a senescence inhibitor and an upregulated target of high-risk human papillomavirus E7. J Virol 79: 14309-14317, 2005.

19. Wise-Draper TM, Allen HV, Jones EE, Habash KB, Matsuo H and Wells SI: Apoptosis inhibition by the human DEK oncoprotein involves interference with p53 functions. Mol Cell Biol 26: 7506-7519, 2016.

20. Liu K, Feng T, Liu J, Zhong M and Zhang S: Silencing of the DEK gene induces apoptosis and senescence in CaSki cervical carcinoma cells via the up-regulation of NF- $\kappa \mathrm{B}$ p65. Biosci Rep 32: 323-332, 2012.

21. Kim DW, Chae JI, Kim JY, Pak JH, Koo DB, Bahk YY and Seo SB: Proteomic analysis of apoptosis related proteins regulated by proto-oncogene protein DEK. J Cell Biochem 106: 1048-1059, 2009.

22. Waldmann T, Eckerich C, Baack M and Gruss C: The ubiquitous chromatin protein DEK alters the structure of DNA by introducing positive supercoils. J Biol Chem 277: 24988-24994, 2002.

23. Kavanaugh GM, Wise-Draper TM, Morreale RJ, Morrison MA, Gole B, Schwemberger S, Tichy ED, Lu L, Babcock GF, Wells JM, et al: The human DEK oncogene regulates DNA damage response signaling and repair. Nucleic Acids Res 39: 7465-7476, 2011.

24. Kappes F, Fahrer J, Khodadoust MS, Tabbert A, Strasser C, Mor-Vaknin N, Moreno-Villanueva M, Bürkle A, Markovitz DM and Ferrando-May E: DEK is a poly(ADP-ribose) acceptor in apoptosis and mediates resistance to genotoxic stress. Mol Cell Biol 28: 3245-3257, 2008

25. Khodadoust MS, Verhaegen M, Kappes F, Riveiro-Falkenbach E, Cigudosa JC, Kim DS, Chinnaiyan AM, Markovitz DM and Soengas MS: Melanoma proliferation and chemoresistance controlled by the DEK oncogene. Cancer Res 69: 6405-6413, 2009.

26. Martinez-Useros J, Rodriguez-Remirez M, Borrero-Palacios A, Moreno I, Cebrian A, Gomez del Pulgar T, del Puerto-Nevado L, Vega-Bravo R, Puime-Otin A, Perez N, et al: DEK is a potential marker for aggressive phenotype and irinotecan-based therapy response in metastatic colorectal cancer. BMC Cancer 14: 965 , 2014.

27. Lin D, Dong X, Wang K, Wyatt AW, Crea F, Xue H, Wang Y, Wu R, Bell RH, Haegert A, et al: Identification of DEK as a potential therapeutic target for neuroendocrine prostate cancer. Oncotarget 6: 1806-1820, 2015.

28. Liu X, Qi D, Qi J, Mao Z, Li X, Zhang J, Li J and Gao W: Significance of DEK overexpression for the prognostic evaluation of non-small cell lung carcinoma. Oncol Rep 35: 155-162, 2016. 